\title{
Urinary Sodium and Potassium Excretion, Mortality, and Cardiovascular Events
}

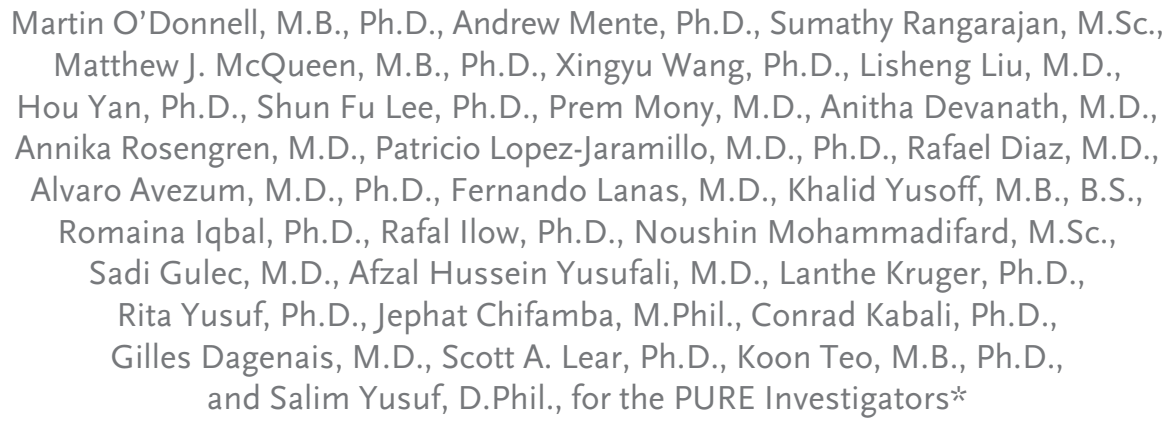

ABSTRACT

The authors' affiliations are listed in the Appendix. Address reprint requests to Dr. O'Donnell at the Population Health Research Institute, David Braley Cardiac, Vascular, and Stroke Research Institute, McMaster University, 2nd Fl., Rm. C2-104, 237 Barton St. E., Hamilton, ON L8L 2X2, Canada, or at odonnm@mcmaster.ca.

*A complete list of the Prospective Urban Rural Epidemiology (PURE) Investigators is provided in the Supplementary Appendix, available at NEJM.org.

This article was updated on August 14, 2014, at NEJM.org.

N Engl J Med 2014;371:612-23. DOI: 10.1056/NEJMoal311889

Copyright @ 2014 Massachusetts Medical Society.

\section{BACKGROUND}

The optimal range of sodium intake for cardiovascular health is controversial.

METHODS

We obtained morning fasting urine samples from 101,945 persons in 17 countries and estimated 24-hour sodium and potassium excretion (used as a surrogate for intake). We examined the association between estimated urinary sodium and potassium excretion and the composite outcome of death and major cardiovascular events.

\section{RESULTS}

The mean estimated sodium and potassium excretion was $4.93 \mathrm{~g}$ per day and $2.12 \mathrm{~g}$ per day, respectively. With a mean follow-up of 3.7 years, the composite outcome occurred in 3317 participants (3.3\%). As compared with an estimated sodium excretion of 4.00 to $5.99 \mathrm{~g}$ per day (reference range), a higher estimated sodium excretion ( $\geq 7.00 \mathrm{~g}$ per day) was associated with an increased risk of the composite outcome (odds ratio, 1.15; 95\% confidence interval [CI], 1.02 to 1.30), as well as increased risks of death and major cardiovascular events considered separately. The association between a high estimated sodium excretion and the composite outcome was strongest among participants with hypertension ( $\mathrm{P}=0.02$ for interaction), with an increased risk at an estimated sodium excretion of $6.00 \mathrm{~g}$ or more per day. As compared with the reference range, an estimated sodium excretion that was below $3.00 \mathrm{~g}$ per day was also associated with an increased risk of the composite outcome (odds ratio, 1.27; 95\% CI, 1.12 to 1.44). As compared with an estimated potassium excretion that was less than $1.50 \mathrm{~g}$ per day, higher potassium excretion was associated with a reduced risk of the composite outcome.

\section{CONCLUSIONS}

In this study in which sodium intake was estimated on the basis of measured urinary excretion, an estimated sodium intake between $3 \mathrm{~g}$ per day and $6 \mathrm{~g}$ per day was associated with a lower risk of death and cardiovascular events than was either a higher or lower estimated level of intake. As compared with an estimated potassium excretion that was less than $1.50 \mathrm{~g}$ per day, higher potassium excretion was associated with a lower risk of death and cardiovascular events. (Funded by the Population Health Research Institute and others.) 
M OST OF THE GLOBAL POPULATION consumes between 3.0 and $6.0 \mathrm{~g}$ of sodium per day (7.5 to $15.0 \mathrm{~g}$ of salt per day). ${ }^{1,2}$ Guidelines on cardiovascular disease prevention recommend a maximum sodium intake of 1.5 to $2.4 \mathrm{~g}$ per day, but achieving this target will require a substantial change in diet for most people. ${ }^{3-5}$

Although clinical trials have shown a reduction in blood pressure with a reduced sodium intake, to our knowledge, no large randomized trial has been conducted to document reductions in the risk of cardiovascular disease with low sodium intake. ${ }^{6}$ Prospective cohort studies have shown inconsistent associations between sodium intake and rates of cardiovascular events and death. $^{6-11}$ Several studies have shown an increased risk of cardiovascular disease or death among people consuming less than $3.0 \mathrm{~g}$ of sodium per day, as compared with average intake, ${ }^{7,9,12-15}$ but many of these studies included people at high cardiovascular risk, ${ }^{13-15}$ who were not representative of the general population. ${ }^{16,17}$ The association between sodium intake and cardiovascular disease is complex and may be modified by other dietary factors, such as potassium intake, which has also been associated with cardiovascular risk. ${ }^{18,19}$

Because of the need for data from large studies examining the association between sodium intake and cardiovascular disease in general populations, ${ }^{8,17}$ we conducted a prospective cohort study that included 101,945 people from five continents. We examined the association of urinary sodium and potassium excretion with death and incident cardiovascular events.

\section{METHODS}

\section{STUDY DESIGN AND PARTICIPANTS}

The Prospective Urban Rural Epidemiology (PURE) study is a large-scale epidemiologic cohort study that enrolled and followed 156,424 persons, 35 to 70 years of age, residing in 628 urban and rural communities in 17 low-, middle-, and high-income countries (Argentina, Bangladesh, Brazil, Canada, Chile, China, Colombia, India, Iran, Malaysia, Pakistan, Poland, South Africa, Sweden, Turkey, United Arab Emirates, and Zimbabwe). ${ }^{20-23}$ Selection of the participants is described in the Supplementary Appendix, available with the full text of this article at NEJM.org. Recruitment began in January 2003. For the cur- rent analysis, we included 101,945 participants who collected early-morning fasting urine samples suitable for analysis. The study was coordinated by the Population Health Research Institute, Hamilton Health Sciences, Hamilton, Ontario, Canada.

\section{PROCEDURES}

A morning fasting midstream urine sample was collected from each participant and frozen at $-20^{\circ} \mathrm{C}$ to $-70^{\circ} \mathrm{C}$. All urine samples were shipped in ambient packaging with the use of STP-250 shipping boxes (Saf-T-Pak) to the Clinical Research Laboratory, Hamilton Health Sciences, Hamilton, Ontario, Canada (the central laboratory for 14 countries), or to the regional laboratory in Beijing; Bangalore, India; or Kocaeli, Turkey, for analyses that used standardized methods. A description of the methods used for performing urinary analyses is provided in the Supplementary Appendix. The Kawasaki formula was used to estimate 24-hour urinary sodium and potassium excretion, and these estimates were used as surrogates for intake. ${ }^{24,25}$ A brief description of the validation of the Kawasaki formula is provided in the article by Mente et al. in this issue of the Journal. ${ }^{26}$

Information on personal medical history and use of prescription medication was obtained by means of questionnaire. Standardized case-report forms were used to capture data on major cardiovascular events and death during follow-up, which were adjudicated with the use of standardized definitions. A description of the ascertainment and adjudication of the outcome events is provided in the Supplementary Appendix. For the current analysis, we included all adjudicated outcome events in the PURE study database through October 16, 2013.

\section{STUDY OVERSIGHT}

The first three authors and the last author conceived the study, supervised all the analyses, assume responsibility for the analyses and the interpretation of data, and wrote the first draft of the manuscript. The study was funded by nonprofit, government, and industry sponsors. The funders of the study had no role in its design or conduct, in the collection, analysis, or interpretation of the data, or in the writing of the manuscript or the decision to submit it for publication. The study was approved by the research ethics committee at each participating center and at Hamilton Health Sciences. All the study participants provided written informed consent.

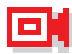

A Quick Take animation is available at NEJM.org 


\section{STATISTICAL ANALYSIS}

Differences in the baseline characteristics among the study participants in the different categories of estimated sodium and potassium excretion were compared with the use of the chi-square test for categorical variables and analysis of variance for continuous variables. We used restrictedcubic-spline plots to explore the shape of the association between the estimated sodium and potassium excretion and the outcomes, fitting a restricted-cubic-spline function with four knots (at the 5th, 35th, 65th, and 95th percentiles). ${ }^{27}$ Our primary outcome measure was the composite of death from any cause and major cardiovascular events (defined as death from cardiovascular causes, stroke, myocardial infarction, or heart failure).

On the basis of our restricted-cubic-spline plots for the primary outcome and the results of previous analyses, ${ }^{13}$ we selected a level of 4.00 to $5.99 \mathrm{~g}$ per day as the reference category for sodium excretion and a level of less than $1.50 \mathrm{~g}$ per day as the reference category for potassium excretion. We performed a multivariable logisticregression analysis with generalized estimating equation models (to account for clustering) ${ }^{28}$ in order to determine the association between estimated urinary sodium and potassium excretion and death and cardiovascular events, using three sequential models. Model 1 (the primary model) was adjusted for age, sex, educational level, ancestry (Asian or non-Asian), alcohol intake (former use, current use, or no use), diabetes mellitus (yes or no), body-mass index (BMI), history of cardiovascular events (yes or no), and current smoking (yes or no), with an additional model that included the ratio of low-density lipoprotein cholesterol to high-density lipoprotein cholesterol. Model 2 also included caloric intake, estimated potassium (or sodium) excretion, and fruit and vegetable intake. In addition to the variables included in models 1 and 2, model 3 included systolic blood pressure, history of hypertension (yes or no), and use of antihypertensive therapy (yes or no) at baseline, because blood pressure is in the putative causal pathway.

To minimize the potential for reverse causation, we conducted analyses that excluded participants with prior cardiovascular disease, those with cancer (at baseline or follow-up), and those with events in the first 2 years of follow-up. We tested for interactions of age, hypertension, sex, ancestry, history of cardiovascular disease, diabe- tes, BMI, and estimated potassium excretion. We explored the potential influence of unmeasured confounders on our estimates of risk using an array-approach sensitivity analysis to determine how strong and imbalanced a confounding effect would need to be to alter the direction of findings. ${ }^{29}$

To further explore the potential effect of imbalanced confounders, we performed propensityscore-matched sensitivity analyses ${ }^{30}$ that compared a high estimated sodium excretion $(\geq 6.00 \mathrm{~g}$ per day) with a moderate level (3.00 to $5.99 \mathrm{~g}$ per day) and that compared a low estimated sodium excretion ( $<3.00 \mathrm{~g}$ per day) with the moderate level. In a secondary analysis, we examined the association between an estimated "usual" level of sodium or potassium excretion and death and cardiovascular disease, with correction for regression dilution bias (with the use of repeated measurements in 448 participants). ${ }^{31}$ All analyses were conducted with the use of SAS software, version 9.2, for the UNIX operating system (SAS Institute).

\section{RESULTS}

\section{STUDY PARTICIPANTS AND OUTCOMES}

The study included 101,945 participants, $42 \%$ of whom were from China. The mean estimated 24hour sodium excretion was $4.93 \mathrm{~g}$, and the mean estimated 24-hour potassium excretion was $2.12 \mathrm{~g}$ (Table 1, and Table S1 in the Supplementary Appendix). The mean systolic and diastolic blood pressures were higher among participants with a higher estimated sodium excretion $(\mathrm{P}<0.001)$. The mean duration of follow-up was 3.7 years, with follow-up completed for $95 \%$ of the participants. The primary composite outcome of death or a major cardiovascular event occurred in 3317 participants (3.3\%): 1976 participants died (650 from cardiovascular causes), 857 had myocardial infarction, 872 had stroke, and 261 had heart failure. Participants may have had more than one cardiovascular event.

\section{ESTIMATED SODIUM EXCRETION AND RISKS OF DEATH AND CARDIOVASCULAR EVENTS}

As compared with an estimated sodium excretion of 4.00 to $5.99 \mathrm{~g}$ per day (the reference category), estimated excretion of $7.00 \mathrm{~g}$ per day or more was associated with increased risks of the primary composite outcome (odds ratio, 1.15; 95\% confidence interval [CI], 1.02 to 1.30), death from any 
cause (odds ratio, 1.25; 95\% CI, 1.07 to 1.48), a major cardiovascular event (odds ratio, 1.16; 95\% CI, 1.01 to 1.34), death from cardiovascular causes (odds ratio, 1.54; 95\% CI, 1.21 to 1.95), and stroke resulting in death or hospitalization (odds ratio, 1.29; $95 \%$ CI, 1.02 to 1.63) on multivariable analysis (Table 2 and Fig. 1, and Table S2 in the Supplementary Appendix). The association between a high estimated sodium excretion $(\geq 7.00 \mathrm{~g}$ per day) and the primary composite outcome, major cardiovascular events, and stroke resulting in death or hospitalization was attenuated and was no longer significant after adjustment for blood pressure or prior diagnosis of hypertension but remained significant for death from any cause (Table 2, and Table S2 in the Supplementary Appendix).

As compared with an estimated sodium excretion of 4.00 to $5.99 \mathrm{~g}$ per day, an estimated excretion of less than $3.00 \mathrm{~g}$ per day was also associated with increased risks of the primary composite outcome (odds ratio, 1.27; 95\% CI, 1.12 to 1.44), death from any cause (odds ratio, 1.38; $95 \%$ CI, 1.15 to 1.66), a major cardiovascular event (odds ratio, 1.30; 95\% CI, 1.13 to 1.50), death from cardiovascular causes (odds ratio, 1.77; 95\% CI, 1.36 to 2.31), and stroke resulting in death or hospitalization (odds ratio, 1.37; 95\% CI, 1.07 to 1.76) (Table 2, and Table S2 in the Supplementary Appendix). These associations remained significant after adjustment for blood pressure or prior diagnosis of hypertension.

\section{ESTIMATED POTASSIUM EXCRETION AND RISKS OF DEATH AND CARDIOVASCULAR EVENTS}

As compared with an estimated potassium excretion of less than $1.50 \mathrm{~g}$ per day, a higher estimated excretion of potassium was associated with a reduction in the risks of death and cardiovascular events on multivariable analysis (Fig. 2 and Table 3); this association was largely related to a reduction in the risk of death (Table S3 in the Supplementary Appendix). There was no evidence of an interaction between estimated potassium and sodium excretion with respect to the primary composite outcome $(\mathrm{P}=0.55)$ (Table S4 in the Supplementary Appendix).

\section{SUBGROUP AND SENSITIVITY ANALYSES}

Hypertension at baseline (defined as a prior diagnosis of hypertension or blood pressure $>140 / 90 \mathrm{~mm} \mathrm{Hg}$ ) modified the association between a high estimated sodium excretion and the composite outcome ( $\mathrm{P}=0.02$ for interaction) (Table S4 in the Supplementary Appendix). In further analysis, there was significantly increased risk observed among participants with baseline hypertension and an estimated sodium excretion of 6.00 to $6.99 \mathrm{~g}$ per day (odds ratio, 1.14; $95 \%$ CI, 1.00 to 1.30 ) or 7.00 g per day or more (odds ratio, 1.21; 95\% CI, 1.05 to 1.40 ), whereas there was no significant association among those without hypertension. There were no other significant subgroup interactions (Tables S4 and S5 in the Supplementary Appendix).

The exclusion of participants with cardiovascular disease (at baseline) or cancer (at baseline or follow-up) or those who had events in the first year of follow-up did not materially affect the findings from the sodium and potassium analyses. When participants with events in the first 2 years were excluded, the associations of a lower ( $<3.00$ g per day) and higher (6.00 to $6.99 \mathrm{~g}$ per day) estimated sodium excretion with the primary outcome were significant (Tables 2 and 3). In a propensity-score-matched analysis that included 21,220 participants, a low estimated sodium excretion ( $<3.00 \mathrm{~g}$ per day), as compared with a moderate level (3.00 to $5.99 \mathrm{~g}$ per day), was associated with an increased risk of the composite outcome (odds ratio, 1.26; 95\% CI, 1.09 to 1.46). In a similar analysis that included 40,618 participants, a high estimated sodium excretion ( $\geq 6.00 \mathrm{~g}$ per day), as compared with a moderate level, was associated with an increased risk of the composite outcome (odds ratio, 1.19; 95\% CI, 1.06 to 1.34) (Table S6 in the Supplementary Appendix). The results of analyses adjusted for regression dilution bias are presented in Figures S1 and S2 in the Supplementary Appendix. The results of the array-approach sensitivity analysis are provided in Table S7 in the Supplementary Appendix.

\section{DISCUSSION}

In this large, international, prospective cohort study, we investigated the association between estimated sodium and potassium excretion (used as surrogates for intake) and the composite of death and cardiovascular outcomes. The lowest risk of death and cardiovascular events was seen among participants with an estimated sodium excretion between $3 \mathrm{~g}$ per day and $6 \mathrm{~g}$ per day. Both higher and lower levels of estimated sodium excretion were associated with increased risk, 


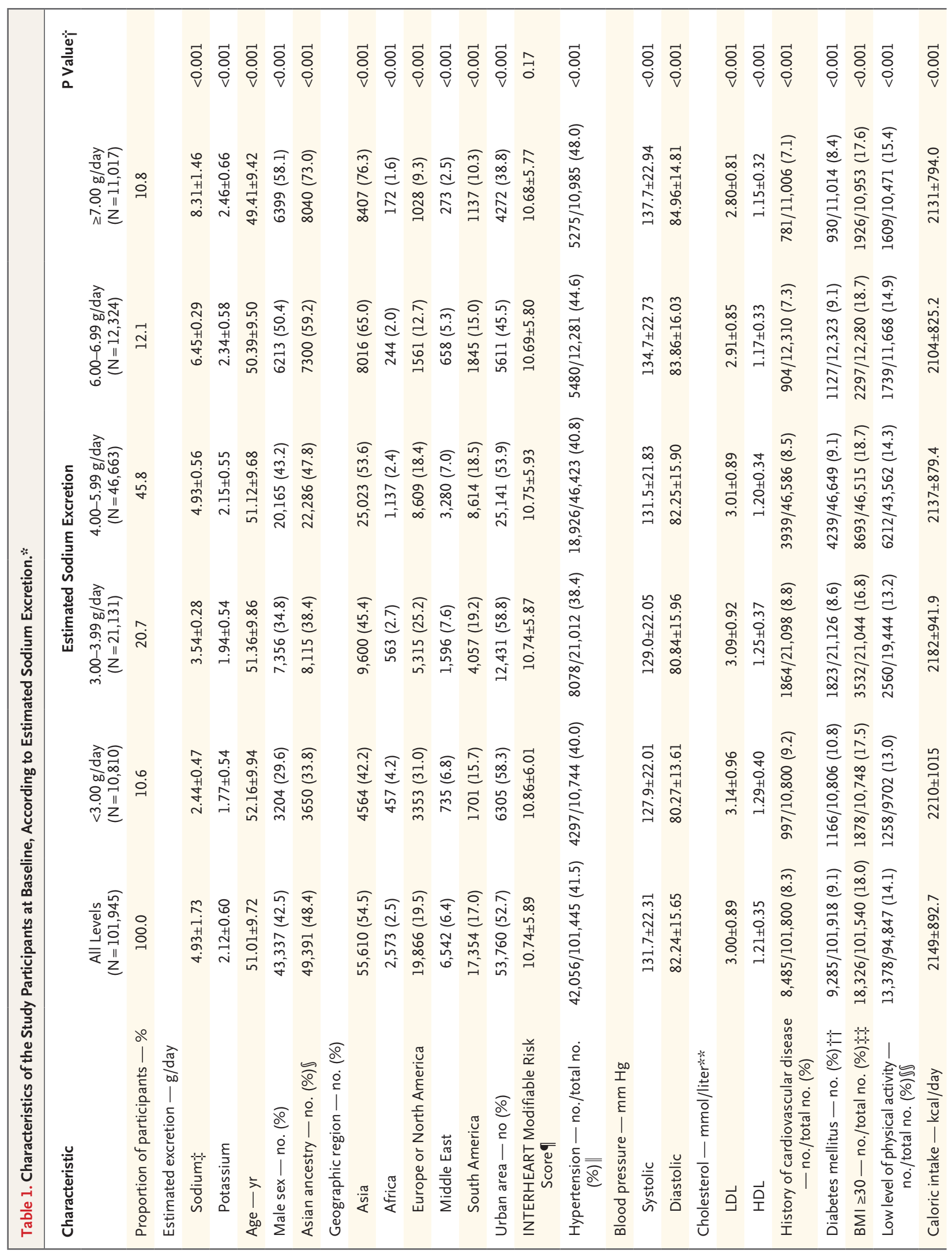




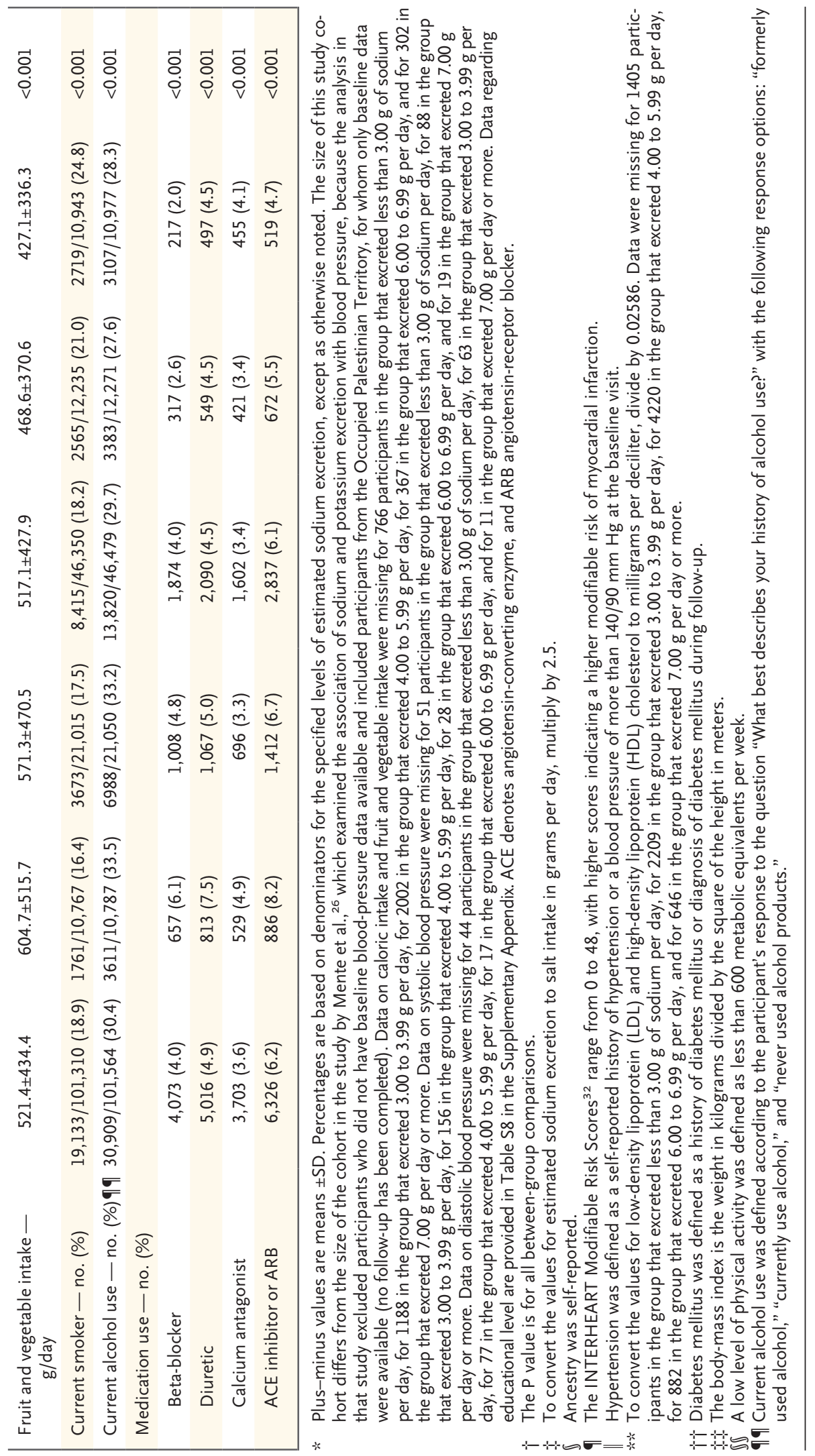

N ENGLJ MED 371;7 NEJM.ORG AUGUST 14, 2014 


\begin{tabular}{|c|c|c|c|c|c|}
\hline \multirow[t]{2}{*}{ Variable } & \multicolumn{5}{|c|}{ Estimated Sodium Excretion } \\
\hline & $\begin{array}{l}<3.00 \mathrm{~g} / \text { day } \\
(\mathrm{N}=10,810)\end{array}$ & $\begin{array}{c}3.00-3.99 \mathrm{~g} / \text { day } \\
(\mathrm{N}=21,131)\end{array}$ & $\begin{array}{l}4.00-5.99 \mathrm{~g} / \text { day } \\
\quad(\mathrm{N}=46,663)\end{array}$ & $\begin{array}{l}6.00-6.99 \mathrm{~g} / \text { day } \\
(\mathrm{N}=12,324)\end{array}$ & $\begin{array}{l}\geq 7.00 \mathrm{~g} / \text { day } \\
(\mathrm{N}=11,017)\end{array}$ \\
\hline $\begin{array}{l}\text { Death or cardiovascular event - } \\
\text { no. of participants (\%) }\end{array}$ & $462(4.3)$ & $662(3.1)$ & $1437(3.1)$ & $391(3.2)$ & $365(3.3)$ \\
\hline \multicolumn{6}{|l|}{ Analysis — odds ratio $(95 \% \mathrm{Cl})$} \\
\hline Univariate analysisł & $1.24(1.09-1.41)$ & $0.96(0.89-1.05)$ & 1.00 & $1.07(0.96-1.19)$ & $1.18(1.05-1.32)$ \\
\hline \multicolumn{6}{|l|}{ Multivariate analysis } \\
\hline Primary analysist & $1.27(1.12-1.44)$ & $1.01(0.93-1.09)$ & 1.00 & $1.05(0.94-1.17)$ & $1.15(1.02-1.30)$ \\
\hline $\begin{array}{l}\text { Analysis including LDL:HDL } \\
\text { ratio }\end{array}$ & $1.30(1.15-1.48)$ & $1.00(0.92-1.09)$ & 1.00 & $1.06(0.94-1.19)$ & $1.18(1.04-1.33)$ \\
\hline $\begin{array}{l}\text { Analysis including dietary } \\
\text { factors } \mathbb{}\end{array}$ & $1.19(1.04-1.35)$ & $1.00(0.92-1.09)$ & 1.00 & $1.06(0.95-1.18)$ & $1.15(1.02-1.30)$ \\
\hline $\begin{array}{l}\text { Analysis including dietary } \\
\text { factors and blood } \\
\text { pressure }\end{array}$ & $1.19(1.05-1.36)$ & $1.01(0.93-1.10)$ & 1.00 & $1.03(0.92-1.15)$ & $1.08(0.96-1.22)$ \\
\hline $\begin{array}{l}\text { Analysis excluding } \\
\text { cardiovascular disease } \\
\text { at baseline } \|\end{array}$ & $1.24(1.07-1.42)$ & $1.00(0.91-1.10)$ & 1.00 & $1.06(0.95-1.19)$ & $1.14(1.01-1.29)$ \\
\hline Analysis excluding cancer\| & $1.26(1.11-1.43)$ & $1.02(0.93-1.11)$ & 1.00 & $1.06(0.95-1.18)$ & $1.15(1.02-1.29)$ \\
\hline Very-low-risk cohort\|*** & $1.62(1.29-2.05)$ & $1.07(0.90-1.26)$ & 1.00 & $1.15(0.98-1.35)$ & $1.14(0.95-1.36)$ \\
\hline $\begin{array}{l}\text { Analysis excluding events } \\
\text { in yr } 1 \|\end{array}$ & $1.33(1.17-1.52)$ & $1.02(0.93-1.13)$ & 1.00 & $1.12(0.99-1.27)$ & $1.16(1.01-1.33)$ \\
\hline $\begin{array}{l}\text { Analysis excluding events } \\
\text { in yr } 1 \text { and } 2 \|\end{array}$ & 1.34 (1.14- 1.57) & $1.04(0.93-1.16)$ & 1.00 & $1.15(1.00-1.32)$ & $1.11(0.96-1.28)$ \\
\hline
\end{tabular}

* Major cardiovascular events included death from cardiovascular causes, myocardial infarction, stroke, and heart failure.

$\dagger$ The univariate analysis was performed with the use of a generalized-estimating-equation model to address clustering of data.

$\neq$ The primary model included age, sex, educational level, ancestry (Asian vs. non-Asian), alcohol intake, body-mass index, and status with respect to diabetes mellitus, a history of cardiovascular events, and current smoking. Additional sensitivity analyses with physical activity (measured in metabolic equivalents per week) included in the model did not materially alter estimates of association (in the cohort with physical-activity data available).

$\int$ Dietary variables included caloric intake, potassium intake, and fruit and vegetable intake.

a Blood-pressure variables included baseline systolic blood pressure, history of hypertension (yes or no), and use of antihypertensive therapy (yes or no).

| The analysis was adjusted for the variables in the primary model.

*** The very-low-risk cohort included 57,988 participants and excluded participants who had prior cardiovascular disease, who had been prescribed medications for cardiovascular disease, who had a history of cancer or a diagnosis of cancer on follow-up, who were smokers, or who had diabetes.

resulting in a J-shaped association curve. The association between a high estimated sodium excretion and increased risk, which was significant only among participants with hypertension, was attenuated after adjustment for blood pressure, suggesting that the adverse effects of high sodium intake may be mediated to some degree by the effects of sodium intake on blood pressure. ${ }^{9,10}$ By contrast, the association between a low estimated sodium excretion and increased risk, which was seen among both patients with hypertension and those without hypertension, was unaffected by adjustment for blood pressure, suggesting that mechanisms other than blood-pressure effects may play a role.

Current guidelines, which recommend a maximum sodium intake of 1.5 to $2.4 \mathrm{~g}$ per day, are based on evidence from largely short-term clinical trials showing that reducing sodium intake from a moderate to a low level results in modest reductions in blood pressure. ${ }^{3,4}$ The projected benefits of low sodium intake with respect to cardiovascular disease are derived from models of data from these blood-pressure trials that assume a linear relationship between sodium intake and blood pressure and between blood pressure and cardio- 
Figure 1. Association of Estimated 24-Hour Urinary Sodium Excretion with Risk of Death and Major Cardiovascular Events.

Panel A shows a restricted-cubic-spline plot of the association between estimated 24 -hour urinary sodium excretion and the composite outcome of death from any cause and major cardiovascular events. The spline curve is truncated at $12.00 \mathrm{~g}$ per day (event rate among participants with sodium excretion $>12.00 \mathrm{~g}$ per day, 8 events in 305 participants). Panel B shows a restrictedcubic-spline plot of the association between estimated sodium excretion and death. The event rate among participants with sodium excretion of more than $12.00 \mathrm{~g}$ per day was 5 events in 305 participants. Panel $C$ shows a restricted-cubic-spline plot of the association between estimated sodium excretion and major cardiovascular events (defined as death from cardiovascular causes, myocardial infarction, stroke, or heart failure). The event rate among participants with sodium excretion of more than $12.00 \mathrm{~g}$ per day was 6 events in 305 participants. All plots were adjusted for age, sex, geographic region, educational level, ancestry (Asian vs. non-Asian), alcohol intake, body-mass index, and status with respect to diabetes mellitus, history of cardiovascular events, and current smoking. Dashed lines indicate $95 \%$ confidence intervals. The median sodium excretion ( $4.72 \mathrm{~g}$ per day) was the reference standard, indicated by the red line. To convert the values for estimated sodium excretion to salt intake in grams per day, multiply by 2.5 .

vascular events. ${ }^{33,34}$ Implicit in these guidelines is the assumption that there is no unsafe lower limit of sodium intake. However, sodium is known to play a critical role in normal human physiology, ${ }^{35}$ and activation of the renin-angiotensinaldosterone system ${ }^{36,37}$ occurs when sodium intake falls below approximately $3.0 \mathrm{~g}$ per day.

A J-shaped association between sodium intake and cardiovascular disease or death has been shown in previous studies. ${ }^{7,9,13,14}$ However, some of these studies included participants at high cardiovascular risk ${ }^{13,14}$ and were vulnerable to biases from reverse causation. Reverse causation may occur when persons with prior cardiovascular disease or increased cardiovascular risk reduce their sodium intake owing to illness or medical recommendations. In the PURE study, the vast majority of participants did not have a history of cardiovascular disease. Although diabetes and history of cardiovascular disease were more common in the group of participants with a low estimated sodium excretion, these participants had a similar overall mean INTERHEART Modifiable Risk Score, ${ }^{32}$ as compared with those who had a moderate estimated sodium excretion. Moreover,

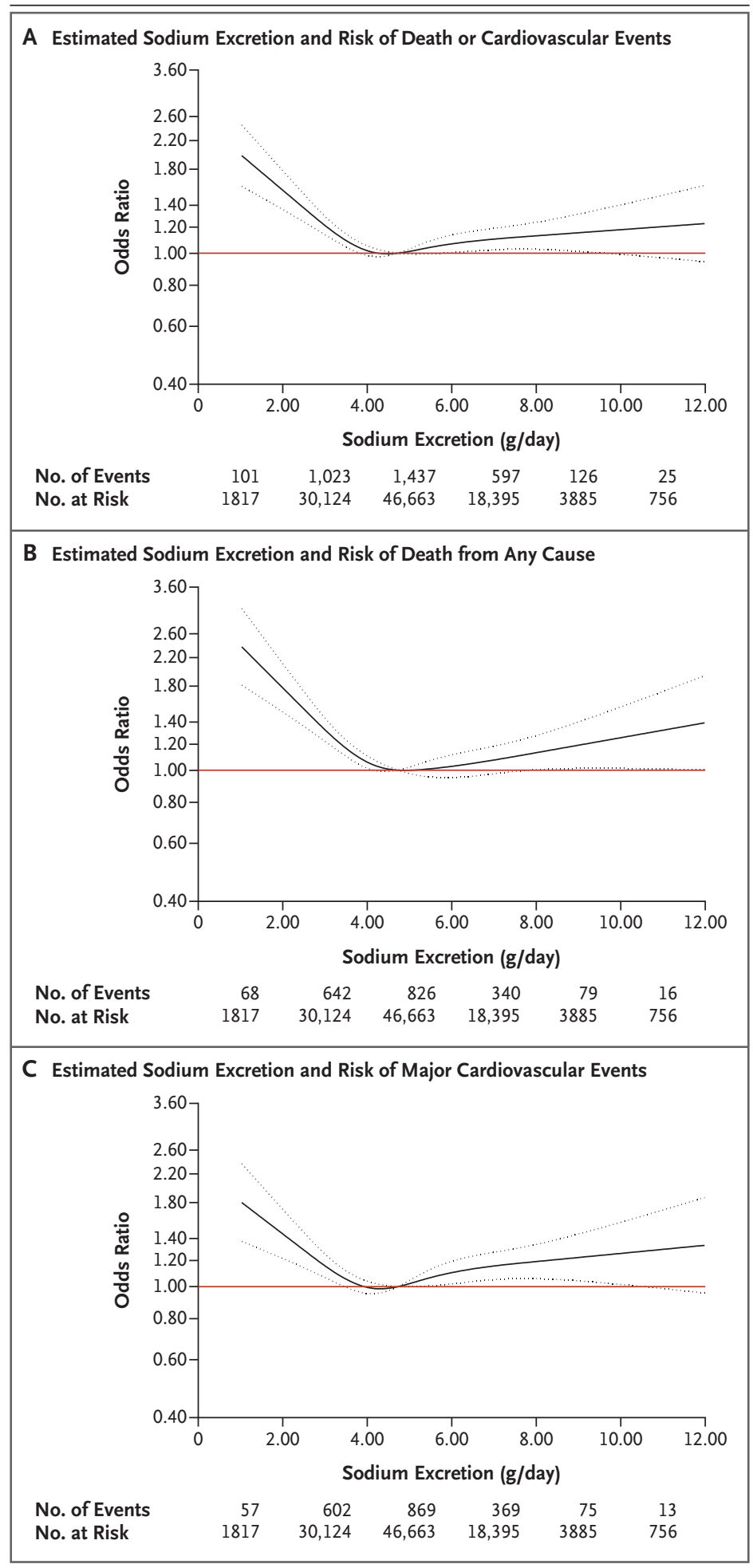

the exclusion of participants with prior cardiovascular disease or cancer, diabetes, or current smoking and the exclusion of those who had events in the first 2 years of follow-up did not 
A Estimated Potassium Excretion and Risk of Death or Cardiovascular Events

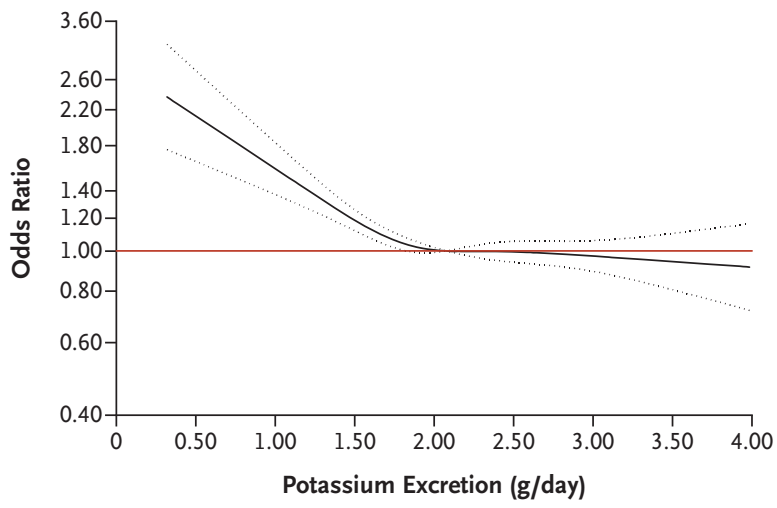

No. of Events No. at Risk

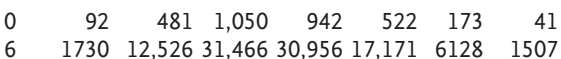

B Estimated Potassium Excretion and Risk of Death from Any Cause

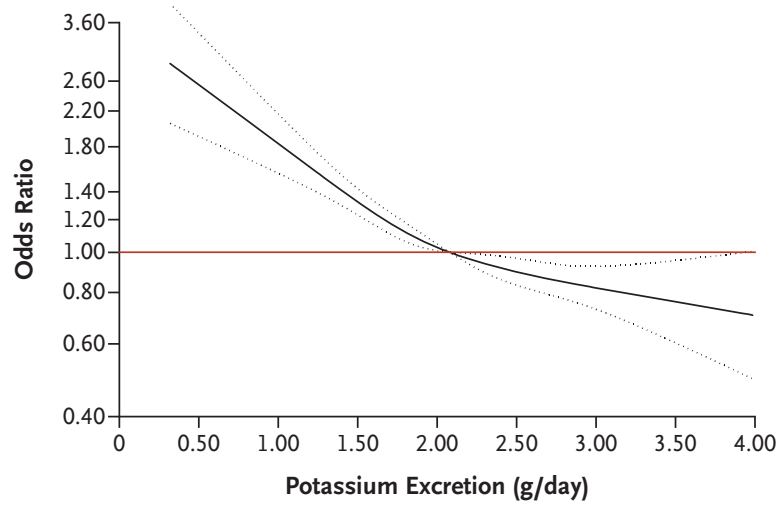

No. of Events No. at Risk

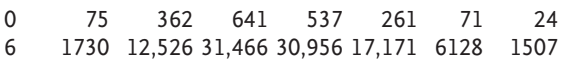

C Estimated Potassium Excretion and Risk of Major Cardiovascular Events

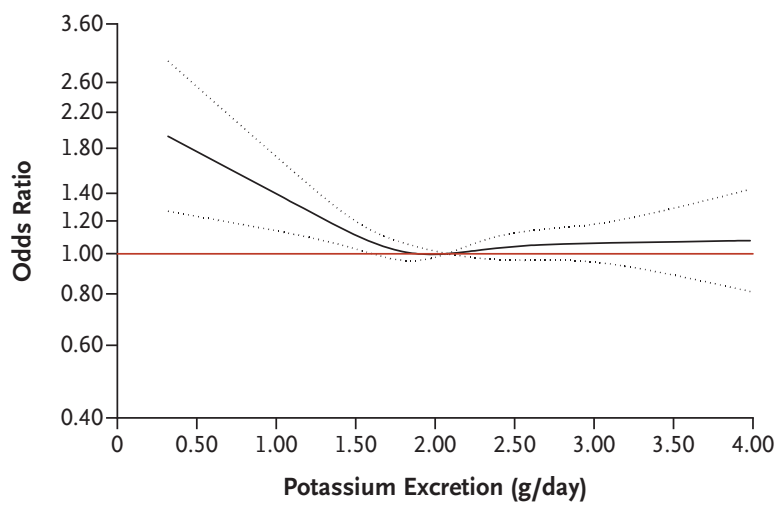

No. of Events No. at Risk

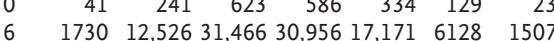

materially alter our findings. Nonetheless, we acknowledge that reverse causation cannot be completely ruled out and may account in part for the increased risk observed in the group of participants with a low estimated sodium excretion. ${ }^{17}$
Figure 2. Association of Estimated 24-Hour Urinary Potassium Excretion with Risk of Death and Major Cardiovascular Events.

Panel A shows a restricted-cubic-spline plot of the association between estimated 24-hour urinary potassium excretion and the composite of death from any cause and major cardiovascular events. The spline curve was truncated at $4.00 \mathrm{~g}$ per day (event rate among participants with potassium excretion $>4.00 \mathrm{~g}$ per day, 13 events in 397 participants). Data on potassium excretion were missing for 58 participants $(0.1 \%)$. Therefore, the sample included in the analysis for the composite outcome of death and major cardiovascular events was 101,887 participants with 3314 events. Panel B shows a restrictedcubic-spline plot of the association between estimated potassium excretion and death from any cause. The event rate among participants with potassium excretion of more than $4.00 \mathrm{~g}$ per day was 4 events in 397 participants. Panel $C$ shows a restricted-cubic-spline plot of the association between estimated potassium excretion and major cardiovascular events (defined as death from cardiovascular causes, myocardial infarction, stroke, or heart failure). The event rate among participants with potassium excretion of more than $4.00 \mathrm{~g}$ per day was 11 events in 397 participants. All plots were adjusted for age, sex, geographic region, educational level, ancestry (Asian vs. non-Asian), alcohol intake, body-mass index, and status with respect to diabetes mellitus, history of cardiovascular events, and current smoking. Dashed lines indicate $95 \%$ confidence intervals. The median level of potassium excretion ( $2.07 \mathrm{~g}$ per day) was the reference standard, indicated by the red line.

We also found that a higher estimated potassium excretion was associated with a lower risk of the composite of death and major cardiovascular events. A small, cluster-randomized, controlled trial, in which participants increased potassium consumption and reduced high sodium consumption through the use of potassiumenriched salt, showed a reduction in cardiovascular mortality among those assigned to the higher-potassium group and could serve as a template for larger, definitive trials. ${ }^{38}$ An increased potassium intake may reduce the risk of death and cardiovascular disease through its effects on blood pressure, or it may simply be a marker of healthy dietary patterns that are rich in potassium (e.g., high consumption of fruit and vegetables). ${ }^{39}$ In our analysis, the association between potassium excretion and the composite outcome was attenuated after adjustment for fruit and vegetable intake and blood pressure.

One potential limitation of our study is that our validated method of estimating sodium and potassium intake used a formula-derived estimate 


\begin{tabular}{|c|c|c|c|c|c|}
\hline \multirow[t]{2}{*}{ Variable } & \multicolumn{5}{|c|}{ Estimated Potassium Excretion } \\
\hline & $\begin{array}{l}<1.50 \mathrm{~g} / \text { day } \\
(\mathrm{N}=14,262)\end{array}$ & $\begin{array}{l}1.50-1.99 \mathrm{~g} / \text { day } \\
\quad(\mathrm{N}=31,466)\end{array}$ & $\begin{array}{l}2.00-2.49 \mathrm{~g} / \text { day } \\
(\mathrm{N}=30,956)\end{array}$ & $\begin{array}{l}2.50-3.00 \mathrm{~g} / \text { day } \\
\quad(\mathrm{N}=17,171)\end{array}$ & $\begin{array}{l}>3.00 \mathrm{~g} / \text { day } \\
(\mathrm{N}=8032)\end{array}$ \\
\hline $\begin{array}{l}\text { Death or cardiovascular event - no. of } \\
\text { participants (\%) }\end{array}$ & $573(4.0)$ & $1050(3.3)$ & $942(3.0)$ & $522(3.0)$ & $227(2.8)$ \\
\hline \multicolumn{6}{|l|}{ Analysis — odds ratio $(95 \% \mathrm{Cl})$} \\
\hline Univariate analysis $\dagger$ & 1.00 & $0.92(0.81-1.04)$ & $0.89(0.78-1.01)$ & $0.91(0.79-1.05)$ & $0.83(0.71-0.98)$ \\
\hline \multicolumn{6}{|l|}{ Multivariate analysis } \\
\hline Primary analysisț & 1.00 & $0.86(0.77-0.97)$ & $0.81(0.73-0.91)$ & $0.86(0.75-0.98)$ & $0.78(0.67-0.91)$ \\
\hline Analysis including LDL:HDL ratio & 1.00 & $0.86(0.77-0.97)$ & $0.81(0.72-0.91)$ & $0.84(0.74-0.96)$ & $0.80(0.68-0.94)$ \\
\hline Analysis including dietary factors $\mathbb{}$ & 1.00 & $0.89(0.79-1.00)$ & $0.84(0.74-0.94)$ & $0.88(0.77-1.00)$ & $0.81(0.69-0.96)$ \\
\hline $\begin{array}{l}\text { Analysis including dietary factors } \\
\text { and blood pressure }\end{array}$ & 1.00 & $0.89(0.80-1.00)$ & $0.86(0.77-0.97)$ & $0.92(0.80-1.05)$ & $0.86(0.73-1.02)$ \\
\hline $\begin{array}{l}\text { Analysis excluding cardiovascular } \\
\text { disease at baseline } \|\end{array}$ & 1.00 & $0.87(0.77-0.98)$ & $0.79(0.70-0.90)$ & $0.87(0.75-1.00)$ & $0.76(0.63-0.91)$ \\
\hline Analysis excluding cancer $\|$ & 1.00 & $0.87(0.78-0.97)$ & $0.81(0.72-0.90)$ & $0.86(0.75-0.98)$ & $0.78(0.66-0.92)$ \\
\hline Very-low-risk cohort $\| * *$ & 1.00 & $0.72(0.60-0.85)$ & $0.71(0.59-0.86)$ & $0.77(0.61-0.96)$ & $0.70(0.53-0.92)$ \\
\hline Analysis excluding events in $\mathrm{yr} 1 \|$ & & $0.89(0.79-1.00)$ & $0.80(0.71-0.91)$ & $0.81(0.70-0.94)$ & $0.77(0.65-0.92)$ \\
\hline $\begin{array}{l}\text { Analysis excluding events in yr } 1 \\
\quad \text { and } 2 \|\end{array}$ & 1.00 & $0.85(0.74-0.98)$ & $0.74(0.63-0.86)$ & $0.79(0.67-0.94)$ & $0.75(0.62-0.92)$ \\
\hline
\end{tabular}

* Data on potassium excretion were missing for 58 participants $(0.1 \%)$. Therefore, the sample included in the analysis for the composite outcome of death and major cardiovascular events was 101,887 participants with 3314 events. Major cardiovascular events included death from cardiovascular causes, myocardial infarction, stroke, and heart failure.

$\dagger$ The univariate analysis was performed with the use of a generalized-estimating-equation model to address clustering of data.

$\neq$ The primary model included age, sex, educational level, ancestry (Asian vs. non-Asian), alcohol intake, body-mass index, and status with respect to diabetes mellitus, a history of cardiovascular events, and current smoking. Data regarding the characteristics of the study participants at baseline and missing data, according to estimated potassium excretion, are provided in Table SI of the Supplementary Appendix. Additional sensitivity analyses with physical activity (measured in metabolic equivalents per week) included in the model did not materially alter estimates of association (in the cohort with physical-activity data available).

$\int$ Dietary factors included the addition of caloric intake, sodium intake, and fruit and vegetable intake.

q Blood-pressure variables included baseline systolic blood pressure, history of hypertension, or use of antihypertensive therapy.

$\|$ The analysis was adjusted for the variables in the primary model.

* The very-low-risk cohort included 57,954 participants and excluded participants who had prior cardiovascular disease, who had a history of cancer or a diagnosis of cancer on follow-up, who had been prescribed medication for cardiovascular disease, who were smokers, or who had diabetes.

of 24-hour urinary excretion and not actual 24-hour urinary collection. This issue, which also applies to the study by PURE investigators Mente et al. ${ }^{26}$ regarding the association between estimated sodium excretion and blood pressure, is discussed further in that article. Our approach is probably less reliable for estimating potassium intake than for estimating sodium intake, since a lower proportion of consumed potassium, as compared with sodium, is excreted in the urine. ${ }^{40}$

Another potential limitation of our study is that a true probability-sampling approach was not undertaken to select our study population. Such a method was not deemed to be feasible, given the many practical constraints of studying sodium excretion in a wide range of countries and settings. The fact that sampling was not random should be considered when interpreting the generalizability of our findings but should not compromise the internal validity of our findings.

An additional potential limitation of our study, as with all observational studies, is the possibility of residual confounding from unmeasured or poorly measured variables. However, our array-approach analysis showed that a confounder effect would need to be quite large to alter the direction of association in the primary multivariable model, especially for the increased risk with low sodium intake. For example, even a strong confounder effect (odds ratio, 22.0) would need to be considerably imbalanced (a difference of $>30$ percentage points) between the low and moderate sodium-intake categories to result in an ad- 
justed odds ratio below 1.0, although a smaller imbalance (a difference of 20 percentage points) would alter the direction of the association for high sodium intake.

Finally, our study provides an epidemiologic comparison of groups that consume different levels of sodium, and it does not provide information on the effect on clinical outcomes of reducing sodium intake. Therefore, our findings should not be interpreted as evidence that the intentional reduction of sodium intake would alter the risk of death or cardiovascular disease.

In conclusion, we investigated the association of estimated sodium and potassium excretion with the risk of death and cardiovascular events in a large, international, prospective cohort study. An estimated sodium intake between $3 \mathrm{~g}$ per day and $6 \mathrm{~g}$ per day was associated with a lower risk of death and cardiovascular events than either a higher or lower estimated level of sodium intake. As compared with an estimated potassium excretion of less than $1.50 \mathrm{~g}$ per day, higher potassium excretion was associated with a reduction in the risk of the composite outcome.

Disclosure forms provided by the authors are available with the full text of this article at NEJM.org.

Supported by the Population Health Research Institute, the Canadian Institutes of Health Research, and the Heart and Stroke Foundation of Ontario and unrestricted grants from several pharmaceutical companies (with major contributions from Boehringer Ingelheim [Germany and Canada], AstraZeneca [Canada], Sanofi-Aventis [France and Canada], Servier, and GlaxoSmithKline, with additional contributions from Novartis and King Pharma), and various national or local organizations in participating countries as follows: Fundación Estudios Clínicos Latinamérica (ECLA) (Argentina); Independent University, Bangladesh, and Mitra and Associates (Bangladesh); Unilever Health Institute (Brazil); Public Health Agency of Canada and Champlain Cardiovascular Disease Prevention Network (Canada); Universidad de la Frontera (Chile); National Center for Cardiovascular Diseases (China); grant from Colciencias (6566-04-18062) (Colombia); the Indian Council of Medical Research (India); grants from the Ministry of Science, Technology, and Innovation of Malaysia (100-IRDC/BIOTEK 16/6/21 [13/2007] and 07-05-IFN-MEB010) and a grant from the Ministry of Higher Education of Malaysia (600-RMI/ LRGS/5/3 [2/2011]), Universiti Teknologi MARA, a grant from the Universiti Kebangsaan Malaysia (UKM-Hejim-Komuniti-15-2010) (Malaysia); a grant from the Polish Ministry of Science and Higher Education (290/W-PURE/2008/0) and Wroclaw Medical University (Poland); North-West University, South Africa-Netherlands Programme for Alternative Development, National Research Foundation, Medical Research Council of South Africa, South Africa Sugar Association, and the Faculty of Community and Health Sciences, University of the Western Cape (South Africa); AFA Insurance, Swedish Council for Working Life and Social Research, Swedish Research Council for Environment, Agricultural Sciences, and Spatial Planning, Swedish Heart-Lung Foundation, Swedish Research Council, the Swedish State (under the Läkar Utbildnings Avtalet Agreement), and the Västra Götaland Region (Sweden); Metabolic Syndrome Society, AstraZeneca, and Sanofi-Aventis (Turkey); and Sheikh Hamdan Bin Rashid Al Maktoum Award for Medical Sciences, Dubai Health Authority (United Arab Emirates). The PURE-Salt substudy was funded by Heart and Stroke Foundation of Ontario.

\section{APPENDIX}

The authors' affiliations are as follows: Population Health Research Institute, Hamilton Health Sciences, McMaster University, Hamilton, ON (M.O., A.M., S.R., M.J.M., S.F.L., C.K., K.T., S.Y.), Laval University Heart and Lung Institute, Quebec City, QC (G.D.), and the Faculty of Health Sciences, Simon Fraser University, and Division of Cardiology, Providence Health Care, Burnaby, BC (S.A.L.) - all in Canada; Health Research Board-Clinical Research Facility, Galway University Hospital, National University of Ireland, Galway (M.O.); Beijing Hypertension League Institute (X.W.) and National Center for Cardiovascular Diseases, Cardiovascular Institute and Fuwai Hospital, Chinese Academy of Medical Sciences (L.L.), Beijing, and Taiyuan Xinghualing District Baling Bridge Community Health Service Center Xinghualing District, Taiyuan Shanxi (H.Y.) — all in China; the Division of Epidemiology and Population Health, St. John's Research Institute, Bangalore, Karnataka, India (P.M., A.D.); Sahlgrenska Academy, University of Gothenburg, Gothenburg, Sweden (A.R.); Fundacion Oftalmologica de Santander Medical School, Universidad de Santander, Floridablanca-Santander, Colombia (P.L.-J.); Estudios Clinicos Latinoamerica, Rosario, Santa Fe, Argentina (R.D.); Dante Pazzanese Institute of Cardiology, São Paulo (A.A.); Universidad de la Frontera, Temuco, Chile (F.L.); Faculty of Medicine, Universiti Teknologi MARA, Selangor, and UCSI University, Kuala Lumpur — both in Malaysia (K.Y.); the Department of Community Health Sciences and Medicine, Aga Khan University, Karachi, Pakistan (R. Iqbal); Wroclaw Medical University, Department of Food Science and Dietetics, Wroclaw, Poland (R. Ilow); Isfahan Cardiovascular Research Center, Isfahan Cardiovascular Research Institute, Isfahan University of Medical Sciences, Isfahan, Iran (N.M.); Ankara University Faculty of Medicine, Department of Cardiology, Ankara, Turkey (S.G.); Hatta Hospital, Dubai Health Authority, Dubai, United Arab Emirates (A.H.Y.); Faculty of Health Science, North-West University, Potchefstroom Campus, Potchefstroom, South Africa (L.K.); School of Life Sciences and the Center for Health, Population, and Development, Independent University, Dhaka, Bangladesh (R.Y.); and the Physiology Department, College of Health Sciences, University of Zimbabwe, Harare, Zimbabwe J.C.).

REFERENCES

1. Brown IJ, Tzoulaki I, Candeias V, Elliott P. Salt intakes around the world: implications for public health. Int J Epidemiol 2009;38:791-813.

2. Powles J, Fahimi S, Micha R, et al. Global, regional and national sodium intakes in 1990 and 2010: a systematic analysis of $24 \mathrm{~h}$ urinary sodium excretion and dietary surveys worldwide. BMJ Open 2013;3(12):e003733.

3. Eckel RH, Jakicic JM, Ard JD, et al. 2013 AHA/ACC guideline on lifestyle management to reduce cardiovascular risk: a report of the American College of Cardi-
ology/American Heart Association Task Force on Practice Guidelines. Circulation 2014;129:Suppl 2:S76-99.

4. Guideline: sodium intake for adults and children. Geneva: World Health Organization, 2012.

5. Kotchen TA, Cowley AW Jr, Frohlich 
ED. Salt in health and disease - a delicate balance. N Engl J Med 2013;368:1229-37.

6. Aburto NJ, Ziolkovska A, Hooper L, Elliott P, Cappuccio FP, Meerpohl JJ. Effect of lower sodium intake on health: systematic review and meta-analyses. BM] 2013;346:f1326.

7. Graudal N, Jurgens G, Baslund B, Alderman MH. Compared with usual sodium intake, low- and excessive-sodium diets are associated with increased mortality: a meta-analysis. Am J Hypertens 2014 April 26 (Epub ahead of print).

8. O'Donnell MJ, Mente A, Smyth A, Yusuf S. Salt intake and cardiovascular disease: why are the data inconsistent? Eur Heart J 2013;34:1034-40.

9. Pfister R, Michels G, Sharp SJ, Luben R, Wareham NJ, Khaw KT. Estimated urinary sodium excretion and risk of heart failure in men and women in the EPICNorfolk study. Eur J Heart Fail 2014 January 20 (Epub ahead of print).

10. Joosten MM, Gansevoort RT, Mukamal KJ et al. Sodium excretion and risk of developing coronary heart disease. Circulation 2014;129:1121-8.

11. Cook NR, Appel LJ, Whelton PK. Lower levels of sodium intake and reduced cardiovascular risk. Circulation 2014;129: 981-9.

12. Stolarz-Skrzypek K, Kuznetsova T, Thijs L, et al. Fatal and nonfatal outcomes, incidence of hypertension, and blood pressure changes in relation to urinary sodium excretion. JAMA 2011;305:1777-85.

13. O'Donnell MJ, Yusuf S, Mente A, et al. Urinary sodium and potassium excretion and risk of cardiovascular events. JAMA 2011;306:2229-38.

14. Thomas MC, Moran J, Forsblom C, et al. The association between dietary sodium intake, ESRD, and all-cause mortality in patients with type 1 diabetes. Diabetes Care 2011;34:861-6.

15. Ekinci EI, Clarke S, Thomas MC, et al. Dietary salt intake and mortality in patients with type 2 diabetes. Diabetes Care 2011;34:703-9.

16. Strom BL, Anderson CA, Ix JH. Sodium reduction in populations: insights from the Institute of Medicine committee. JAMA 2013;310:31-2.

17. Cobb LK, Anderson CA, Elliott P, et al. Methodological issues in cohort studies that relate sodium intake to cardiovascular disease outcomes: a science advisory from the American Heart Association. Circulation 2014;129:1173-86.

18. Aburto NJ, Hanson S, Gutierrez H,
Hooper L, Elliott P, Cappuccio FP. Effect of increased potassium intake on cardiovascular risk factors and disease: systematic review and meta-analyses. BMJ 2013; 346:f1378

19. Cook NR, Obarzanek E, Cutler JA, et al. Joint effects of sodium and potassium intake on subsequent cardiovascular disease: the Trials of Hypertension Prevention follow-up study. Arch Intern Med 2009; 169:32-40.

20. Yusuf $S$, Islam S, Chow CK, et al. Use of secondary prevention drugs for cardiovascular disease in the community in high-income, middle-income, and lowincome countries (the PURE Study): a prospective epidemiological survey. Lancet 2011;378:1231-43

21. Corsi DJ, Subramanian SV, Chow CK, et al. Prospective Urban Rural Epidemiology (PURE) study: baseline characteristics of the household sample and comparative analyses with national data in 17 countries. Am Heart J 2013;166:636-46.

22. Chow CK, Teo KK, Rangarajan S, et al. Prevalence, awareness, treatment, and control of hypertension in rural and urban communities in high-, middle-, and lowincome countries. JAMA 2013;310:959-68. 23. Teo K, Lear S, Islam S, et al. Prevalence of a healthy lifestyle among individuals with cardiovascular disease in high-, middle- and low-income countries: the Prospective Urban Rural Epidemiology (PURE) study. JAMA 2013;309:1613-21.

24. Kawasaki T, Itoh $K$, Uezono K, Sasaki H. A simple method for estimating $24 \mathrm{~h}$ urinary sodium and potassium excretion from second morning voiding urine specimen in adults. Clin Exp Pharmacol Physiol 1993;20:7-14. [Erratum, Clin Exp Pharmacol Physiol 1993;20:199.]

25. Mente A, O'Donnell MJ, Dagenais G, et al. Validation and comparison of three formulae to estimate sodium and potassium excretion from a single morning fasting urine compared to 24-h measures in 11 countries. J Hypertens 2014;32:100514

26. Mente A, O'Donnell MJ, Rangarajan $S$, et al. Association of urinary sodium and potassium excretion with blood pressure. N Engl J Med 2014;371:601-611.

27. Harrell F. Regression modelling strategies with applications to linear models, logistic regression, and survival analysis. New York: Springer-Verlag, 2001

28. Hanley JA, Negassa A, Edwardes MD, Forrester JE. Statistical analysis of correlated data using generalized estimating equations: an orientation. Am J Epidemiol 2003;157:364-75.

29. Schneeweiss S. Sensitivity analysis and external adjustment for unmeasured confounders in epidemiologic database studies of therapeutics. Pharmacoepidemiol Drug Saf 2006;15:291-303.

30. D’Agostino RB Jr. Propensity score methods for bias reduction in the comparison of a treatment to a non-randomized control group. Stat Med 1998;17: 2265-81.

31. Lewington S, Whitlock G, Clarke R, et al. Blood cholesterol and vascular mortality by age, sex, and blood pressure: a meta-analysis of individual data from 61 prospective studies with 55,000 vascular deaths. Lancet 2007;370:1829-39. [Erratum, Lancet 2008;372:292.]

32. McGorrian C, Yusuf S, Islam S, et al. Estimating modifiable coronary heart disease risk in multiple regions of the world: the INTERHEART Modifiable Risk Score. Eur Heart J 2011;32:581-9.

33. Bibbins-Domingo K, Chertow GM, Coxson PG, et al. Projected effect of dietary salt reductions on future cardiovascular disease. N Engl J Med 2010;362:590-9.

34. Coxson PG, Cook NR, Joffres M, et al. Mortality benefits from US populationwide reduction in sodium consumption: projections from 3 modeling approaches. Hypertension 2013;61:564-70.

35. Heaney RP. Sodium: how and how not to set a nutrient intake recommendation. Am J Hypertens 2013;26:1194-7.

36. Brunner HR, Laragh JH, Baer L, et al. Essential hypertension: renin and aldosterone, heart attack and stroke. N Engl J Med 1972;286:441-9.

37. Graudal NA, Hubeck-Graudal T, Jurgens G. Effects of low sodium diet versus high sodium diet on blood pressure, renin, aldosterone, catecholamines, cholesterol, and triglyceride. Cochrane Database Syst Rev 2011;11:CD004022.

38. Chang HY, Hu YW, Yue CS, et al. Effect of potassium-enriched salt on cardiovascular mortality and medical expenses of elderly men. Am J Clin Nutr 2006;83: 1289-96.

39. Mente A, Irvine EJ, Honey RJ, Logan AG. Urinary potassium is a clinically useful test to detect a poor quality diet. J Nutr 2009;139:743-9.

40. Holbrook JT, Patterson KY, Bodner JE, et al. Sodium and potassium intake and balance in adults consuming self-selected diets. Am J Clin Nutr 1984;40:786-93.

Copyright (๑) 2014 Massachusetts Medical Society.

MY NEJM IN THE JOURNAL ONLINE

Individual subscribers can store articles and searches using a feature on the Journal's website (NEJM.org) called "My NEJM."

Each article and search result links to this feature. Users can create personal folders and move articles into them for convenient retrieval later. 